\title{
Twenty years of prehospital coronary care
}

\author{
J S GEDDES \\ From the Cardiac Department, Royal Victoria Hospital, Belfast, Northern Ireland
}

By 1965 the possibility of preventing deaths from arrhythmia among those stricken with coronary attacks was already well established. The realisation that most of these deaths occur shortly after onset and therefore outside hospital led to the recognition that hospital coronary care units were of limited value because most patients who reached them were already either convalescent or moribund. Professor JF Pantridge (then Dr) and I therefore decided to arrange that trained staff with equipment should reach the coronary victim as soon as possible after the onset of the attack. A mobile coronary care unit was introduced in Belfast on 1 January $1966 .^{1}$ At that time the components had to be assembled to make a defibrillation system available.

We soon demonstrated that resuscitation from ventricular fibrillation could be achieved in the prehospital setting. ${ }^{23}$ The system was successful in reaching the majority of patients early and this reduced the disparity in place and time between the need for coronary care facilities and their availability. Furthermore, deaths during transport to hospital were virtually eliminated among patients receiving prehospital care.

During the subsequent years prehospital coronary care systems were established in many parts of the world. ${ }^{4}$ Some of these units were staffed by physicians but, particularly in the United States, the tendency grew for staffing to be provided by paramedical workers, technicians, or a tiered combination of both. In Britain a unit staffed by specially trained ambulancemen was set up in Brighton in $1971 .^{5}$ Against the background of these developments it is useful, after two decades, to survey the achievements of prehospital systems and to consider why the principle has been accepted with enthusiasm in some countries and not in others.

As experience of the acute phase of infarction in

Requests for reprints to Dr J S Geddes, Cardiac Department, Royal Victoria Hospital, Grosvenor Road, Belfast BT12 6BA, Northern Iretand.
Belfast increased it became apparent that early management had beneficial effects extending far beyond the prompt relief of pain and the correction of ventricular fibrillation at the place of onset or during transit. Some life threatening arrhythmias may have been prevented by the use of antiarrhythmic drugs and many episodes of ventricular fibrillation were corrected in hospital before the patients would normally have come under intensive care. Of perhaps even greater importance were the manifestations of autonomic disturbance that were commonly present during the early hours of infarction and which could undoubtedly trigger ventricular fibrillation. ${ }^{6-8}$ Among patients seen within 30 minutes, one half had evidence of vagal overactivity (almost half of these had systolic blood pressure of $\leqslant 80 \mathrm{~mm} \mathrm{Hg}$ ) and a third had evidence of inappropriate sympathetic discharge. Combined autonomic disturbance was not uncommon.

Correction of the acute disturbances conferred unexpected benefits. Among patients aged 70 or less seen and treated within the first hour, hospital morbidity was only $9 \%$ and cardiogenic shock was rare. Pantridge's hypothesis, in 1970, that early treatment by permitting the correction of adverse abnormalities of heart rate and blood pressure might prevent unnecessary extension of the infarct ${ }^{9}$ led to much interest in the limitation of infarct size, an interest which continues.

\section{Mechanisms of the beneficial effect of early care}

Insufficient attention has been paid to the two distinct mechanisms by which early prehospital care can reduce morbidity and mortality. Although the skills of trained ambulancemen and paramedical workers should not be underestimated, the unit manned by non-physicians seems to have more to contribute to resuscitation than to the correction of disturbances of rate, rhythm, and blood pressure, a 
process which often requires titration with atropine, $\beta$ blocking drugs, or antiarrhythmic agents to avoid the vicious cycle of inexorable extension of the infarct and increasing pump failure.

\section{RESUSCITATION}

The lessons learned in the hospital coronary care unit have been echoed by development of facilities for out of hospital correction of ventricular fibrillation, notably in Seattle, where a prehospital system was started in $1970 .^{10}$ Emergency medical technicians (firemen), who are widely dispersed in the community, take an average of three minutes to reach a patient. They provide basic life support until paramedical workers arrive a few minutes later.

The baseline survival rate for this approach was about $20 \% \cdot{ }^{11}$ With the addition of refinements salvage was greatly increased. Immediate cardiopulmonary resuscitation by trained bystander members of the public doubled the percentage of survivors ${ }^{12}$; when the delay in defibrillation was also short, $50 \%$ survival was achieved. ${ }^{13}$ Similar results were obtained when subsequently the first responders were able to defibrillate without waiting for arrival of the paramedical workers. ${ }^{14}$ The potential survival rate under ideal conditions in which a defibrillator is available to the person activating the emergency system is estimated to be as high as $70 \% .{ }^{15}$ Neurological recovery and long term health status were generally better when resuscitation and defibrillation had not been delayed. ${ }^{1416}$

The benefits vary according to local circumstances. ${ }^{17}$ Nevertheless, the advantages of streamlining cardiopulmonary resuscitation, definitive care, or both have been confirmed in other parts of the United States ${ }^{17-19}$ and in Britain ${ }^{20}$ and Sweden. ${ }^{21}$

\section{LIMITATION OF INFARCT SIZE}

Units manned by physicians excel at the prehospital stabilisation of patients with suspected acute infarction. Economic considerations dictate that these units cannot be so numerous or so widely distributed as those staffed by paramedical workers; nevertheless, many patients with ventricular fibrillation have been resuscitated by such units. ${ }^{22}{ }^{23}$ Equally important has been the confirmation elsewhere ${ }^{23}$ of the Belfast finding ${ }^{22}$ that the outlook of patients treated early is better than that of those seen later after onset. In addition, community mortality among persons below age 70 fell when prehospital care was introduced in Charlottesville, Virginia, and not all of the observed reduction could be ascribed to resuscitation. ${ }^{24}$

Resuscitation results in a readily identifiable salvage but the specific effects of the early treatment of infarction in preventing life threatening arrhythmia and extension of myocardial necrosis are less easily quantified. Recent evidence supports the view that these effects are substantial. ${ }^{25}$ Community mortality from coronary attacks was surveyed in two comparable areas of Northern Ireland. One area had prehospital coronary care and the other had a hospital coronary care unit only. Mortality in the area with a mobile unit was significantly less than that in the other area and the difference was conspicuous in the younger age groups. Among persons aged $<65$ community mortality was $38 \%$ lower, and this difference was not attributable to prehospital resuscitation.

\section{THE NOTTINGHAM STUDIES}

Earlier attempts at the evaluation of the possible impact of prehospital care in Nottingham yielded disappointing results, ${ }^{26-28}$ and undoubtedly these, together with the result of the Bristol study of home versus hospital treatment of myocardial infarction, ${ }^{29}$ delayed the recognition of the value of prehospital care in Britain. The absence of an appreciable reduction in mortality in Nottingham was ascribed to difficulties in arranging for the unit to reach many patients while it was possible to alter the course of their coronary attacks. ${ }^{30}$ The Nottingham workers largely based their criticism of the relevance of the Belfast data on the finding that surviving patients seen by the Nottingham mobile unit belonged to a low risk group. They apparently considered that the low mortality among patients managed during the prehospital phase elsewhere was the result of similar selection of low risk patients. But they overlooked the fact that the relevant evidence supporting the value of prehospital care was derived from a comparison of the outcome for patients seen and treated early with that for patients first seen after a longer delay. 2223

The studies performed by the Nottingham workers gave an invaluable insight into the difficulties inherent in initiating an effective prehospital service. It is unfortunate that their results began to appear immediately after the publication in 1975 of the recommendations of the Joint Working Party of the Royal College of Physicians and the British Cardiac Society on the care of the patient with coronary heart disease. ${ }^{31}$ The Department of Health and Social Security did not, as recommended in the working party report, encourage the development of mobile coronary care but rather placed an embargo on the extension of schemes of advanced training for ambulancemen. ${ }^{32} \mathrm{Had}$ the recommendations of the working party on the further development of prehospital care (the exact means depending on local conditions and requirements), on the instruction of 
the public in resuscitation, and on the importance and means of summoning help quickly been received by the Department of Health and Social Security with the enthusiasm and flexibility of approach envisaged in their report, there can now be no doubt that very many lives would have been saved during the intervening decade.

\section{The portable defibrillator}

The "portable" defibrillation system carried in the first mobile unit in Belfast weighed $50 \mathrm{~kg}$. Clearly the wide proliferation of prehospital schemes would have been impossible but for the advent of more easily portable machines. In 1974 a miniature defibrillator weighing only $3.2 \mathrm{~kg}$ appeared..$^{33}$ The waveform of $12 \mathrm{~ms}$ duration delivered by this machine had been found by Peleska to be optimal for defibrillation of laboratory animals. ${ }^{34}$

A signpost to possible further miniaturisation was the observation by the Belfast workers that a stored energy of only $200 \mathrm{~J}$ is sufficient to defibrillate the hearts of $95 \%$ of patients. ${ }^{35}$ The efficacy of low energy levels was confirmed by others. ${ }^{36} 37$ Repeated shocks of $400 \mathrm{~J}$ stored energy cause myocardial damage in animals. ${ }^{38}$ Shocks of this magnitude, which are usually not necessary clinically, may cause functional disturbance in man. ${ }^{37}$

Because the ease with which delay of defibrillation in the community may be avoided will be inversely proportional to the size, weight, and cost of defibrillators, the availability of a low energy machine could contribute to the survival of many more patients. Because of their additional bulk and uncertainty about the adequacy of rhythm interpretation, combined defibrillator/oscilloscopes will be of limited value for use by first responders. The long awaited miniaturised automatic external defibrillator is already undergoing clinical evaluation. ${ }^{3940}$ If minimally trained technicians or family members of those at risk could use these machines, the delay inherent in awaiting the arrival of more skilled help would be avoided. Domiciliary defibrillation facilities must increase because many of the survivors of prehospital cardiac arrest will be at considerable risk of recurrence.

\section{The future of prehospital coronary care}

Fortunately, the Department of Health and Social Security has decided to encourage the development of prehospital care through the extended training of ambulancemen. In addition, a unique programme of instruction of the general public in basic life support via the media, known as the "Save a Life Campaign," is just beginning under the auspices of the
Royal Society of Medicine. These developments when fully implemented will undoubtedly prevent many deaths from arrhythmia after acute coronary attacks. Even in Belfast, which is served by two mobile units, in a one year period 128 sudden and premature prehospital deaths were identified. Many might have been prevented by immediate appropriate action by someone present at the time. ${ }^{41}$ An estimate based mainly on data from Auckland indicates that prehospital resuscitation appears to have made the greatest single contribution $(40 \%)$, attributable to medical measures, to the reduction in coronary mortality yet the incidence of sudden death there has fallen by only $16 \%{ }^{42}$

The energetic application of public education programmes in cardiopulmonary resuscitation of the type already devised in Britain ${ }^{43}$ and the United States ${ }^{44}$ is required. Such education should be especially aimed at those most likely to witness a cardiac arrest, ${ }^{45}$ such as families of middle aged men and of others known to be at special risk. Because even moderately efficient resuscitation may suffice during the first few minutes before the arrival of advanced life support, it may be rewarding to devise and teach a simplified technique for use by the "occasional bystander".

Will a nationwide prehospital system based mainly on the emergency ambulance service, as envisaged by the Department of Health and Social Security, be sufficient to meet present and future needs? Can ambulancemen give drugs to limit infarct size? As emphasis is increasingly placed on the prevention rather than the limitation of infarction, the need for the administration of thrombolytic agents will increase. ${ }^{46}$ Perhaps hospitals could give guidance on the telephone in such circumstances. For the present, however, these needs can best be met in Britain by using doctors on the teams. In the best prehospital system an ultrarapid emergency ambulance tier (several vehicles) would be supported by a hospital tier (one or two teams) resembling the prehospital scheme started in Charlottesville in $1971 .^{24}$ Such a system will shortly come into operation in Ballymena as an extension of a well established medically manned mobile unit (C Wilson, personal communication).

Comprehensive coverage of city and rural areas will require considerable ingenuity and it is here that organisations such as the British Association for Immediate Care and the Association of Emergency Medical Technicians will play an increasingly important coordinating role. In rural areas the general practitioner can often reach the stricken individual first. Defibrillation by general practitioners has been shown to be highly rewarding. ${ }^{47}$ Delineation of the responsibilities of the family doctors and of the 
emergency ambulance service in each area could result in worthwhile economies.

The proficiency of hospital doctors in basic and advanced life support must keep pace with the progress being made by citizens and paramedical workers. When the cardiopulmonary resuscitation skills of junior medical hospital staff were tested in some hospitals in Britain and the United States the results were disappointing. ${ }^{48-50}$ Medical schools and physicians in related specialities must ensure that public education and training are paralleled by adequate teaching of the necessary skills at undergraduate and postgraduate levels.

\section{References}

1 Pantridge JF, Geddes JS. Cardiac arrest after myocardial infarction. Lancet 1966;i:807-8.

2 Geddes JS, Pantridge JF. The effect of rapid hospital admission on the mortality from acute myocardial infarction [Abstract]. $Q \mathcal{F}$ Med 1967;36:599-600.

3 Pantridge JF, Geddes JS. A mobile intensive-care unit in the management of myocardial infarction. Lancet 1967;ii:271-3.

4 Pantridge JF, Adgey AAJ, Geddes JS, Webb SW. The acute coronary attack. Tunbridge Wells: Pitman Medical, 1975:130-6.

5 White NM, Parker WS, Binning RA, Kimber ER, Ead HW, Chamberlain DA. Mobile coronary care provided by ambulance personnel. $\mathrm{Br} \mathrm{Med} \mathcal{f}$ 1973;iii:618-22.

6 Adgey AAJ, Geddes JS, Mulholland HC, Keegan DAJ, Pantridge JF. Incidence, significance, and management of early bradyarrhythmia complicating acute myocardial infarction. Lancet 1968;ii: 1097-101.

7 Webb SW, Adgey AAJ, Pantridge JF. Autonomic disturbance at onset of acute myocardial infarction. Br Med F 1972;iil:89-92.

8 Pantridge JF, Webb SW, Adgey AAJ, Geddes JS. The first hour after the onset of acute myocardial infarction. In: Yu PN, Goodwin JF, eds. Progress in cardiology. Vol 3. Philadelphia: Lea and Febiger, 1974:173-88.

9 Pantridge JF. The effect of early therapy on the hospital mortality from acute myocardial infarction [Abstract]. Qf Med 1970;39:621-2.

10 Cobb LA, Alvarez H III. Medic 1: The Seattle system for the management of out-of-hospital emergencies. In: National Conference of Standards for Cardiopulmonary Resuscitation (CPR) and Emergency Cardiac Care (ECC). Dallas: American Heart Association, 1975:179-82.

11 Cobb LA, Baum RS, Alverez H III, Schaffer WA. Resuscitation from out-of-hospital ventricular fibrillation: 4 years follow-up. Circulation 1975; 52(suppl 3):223-8.

12 Thompson RG, Hallstrom AP, Cobb LA. Bystanderinitiated cardiopulmonary resuscitation in the management of ventricular fibrillation. Ann Intern Med 1979;90:737-40.
13 Cobb LA, Hallstrom AP. Community-based cardiopulmonary resuscitation: what have we learned? $A n n$ NY Acad Sci 1982;382:330-42.

14 Weaver WD, Copass MK, Bufi D, Ray R, Hallstrom AP, Cobb LA. Improved neurologic recovery and survival after early defibrillation. Circulation 1984; 69:943-8.

15 Weaver WD, Cobb LA, Hallstrom AP, Fahrenbruch C, Copass MK, Ray R. Factors influencing survival after out-of-hospital cardiac arrest. $\mathcal{f} \mathrm{Am}$ Coll Cardiol 1986;7:752-7.

16 Bergner L, Bergner M, Hallstrom AP, Eisenberg MS, Cobb LA. Service factors and health status of survivors of out-of-hospital cardiac arrest. Am $\mathcal{F}$ Emerg Med 1983;1:259-63.

17 Guzy PM, Pearce ML, Greenfield S. The survival benefit of bystander cardiopulmonary resuscitation in a paramedic served metropolitan area. Am $\mathcal{F}$ Public Health 1983;73:766-9.

18 Eisenberg M, Bergner L, Hallstrom A. Paramedic programs and out-of-hospital cardiac arrest: 1. Factors associated with successful resuscitation. Am $\mathcal{F}$ Public Health 1979;69:30-8.

19 Stults KR, Brown DD, Schug VL, Bean JA. Prehospital defibrillation performed by emergency medical technicians in rural communities. $N$ Engl $\mathcal{f}$ Med 1984;310:219-23.

20 Mackintosh AF, Crabb ME, Grainger R, Williams JH. Chamberlain DA. The Brighton resuscitation ambulances: review of 40 consecutive survivors of out-ofhospital cardiac arrest. Br Med f 1978;i:1115-8.

21 Wennerblom B, Ekström L, Holmberg S. Resuscitation of patients in cardiac arrest outside hospital. Comparison of two different organizations of mobile coronary care in one community. Eur Heart $\mathcal{F}$ 1984;5:21-6.

22 Adgey AAJ, Allen JD, Geddes JS, et al. Acute phase of myocardial infarction. Lancet 1971;ii:501-4.

23 Grace WJ, Chadbourn JA. The first hour in acute myocardial infarction. Heart Lung 1974;3:736-41.

24 Crampton RS, Aldrich RF, Gascho JA, Miles JR, Stillerman R. Reduction of prehospital, ambulance and community coronary death rates by the community-wide emergency cardiac care system. Am f Med 1975;58:151-65.

25 Mathewson ZM, McCloskey BG, Evans AE, Russell CJ, Wilson C. Mobile coronary care and community mortality from myocardial infarction. Lancet 1985;i:441-4.

26 Hampton JR. Importance of patient selection in evaluating a cardiac ambulance service. $\mathrm{Br} \mathrm{Med} \mathcal{f}$ 1976; i:201-3.

27 Hill JD, Hampton JR. Mode of referral to hospital of patients with heart attacks: relevance to home care and special ambulance services. $\mathrm{Br} \mathrm{Med} f$ 1976;ii:1035-6.

28 Hampton JR, Dowling M, Nicholas C. Comparison of results from a cardiac ambulance manned by medical or non-medical personnel. Lancet 1977;i:526-9.

29 Mather HG, Pearson NG, Read KLQ, et al. Acute myocardial infarction: home and hospital treatment. Br Med F 1971;iii:334-8. 
30 Hampton JR. Coronary patient-early treatment. Br Heart F 1981;46:117-20.

31 The Royal College of Physicians of London and the British Cardiac Society. The care of the patient with coronary heart disease: report of a joint working party. F $R$ Coll Physicians Lond 1975;10:5-46.

32 Health Services Development Ambulance Service: advanced training for ambulancemen. London: DHSS, 1976. Health Notice HN (76) 204.

33 Pantridge JF, Adgey AAJ, Webb SW, Anderson J. Electrical requirements for ventricular defibrillation. Br Med F 1975;ii:313-5.

34 Peleska B. Optimal parameters of electrical impulses for defibrillation by condenser discharges. Circ Res 1966;18:10-7.

35 Campbell NPS, Webb SW, Adgey AAJ, Pantridge JF. Transthoracic ventricular defibrillation in adults. Br Med F 1977;ii:1379-81.

36 Gascho JA, Crampton RS, Cherwek ML, Sipes JN, Hunter FP, O'Brien WM. Determinants of ventricular defibrillation in adults Circulation 1979;60: 231-40.

37 Weaver WD, Cobb LA, Copass MK, Hallstrom AP. Ventricular defibrillation-a comparative trial using 175-J and 320-J shocks. $N$ Engl $\mathcal{F}$ Med 1982; 307:1101-6.

38 Patton JN, Allen JD, Pantridge JF. The effects of shock energy, propranolol, and verapamil on cardiac damage caused by transthoracic countershock. Circulation 1984;69:357-68.

39 Weaver WD, Hill D, Fahrenbruch C, et al. Value of field experience in improving automatic external defibrillators [Abstract]. $\mathcal{F} \mathrm{Am}$ Coll Cardiol 1986; 7(suppl A):72.

40 Cobb LA. Sudden death-a community problem.
In: Geddes JS, ed. The management of the acute $\subseteq$ coronary attack. London: Academic Press, 1986: 105-22.

41 McIlwaine WJ, Donnelly MDI, Mallaghan M, et al. Deaths from ischaemic heart disease in Belfast. Br Heart F 1986;55:330-5.

42 Beaglehole R. Medical management and the decline in mortality from coronary heart disease. $\mathrm{Br} \mathrm{Med} \mathcal{f}$ 1986;292:33-5.

43 Vincent R, Martin B, Williams G, Quinn E, Robertson $\overrightarrow{0}$ G, Chamberlain DA. A community training scheme: in cardiopulmonary resuscitation. $\mathrm{Br} \mathrm{Med} \mathcal{F} 1984 ; \vec{\omega}$ 288:617-20.

44 Cobb LA, Hallstrom AP, Thompson RG, Mandel LP, Copass MK. Community cardiopulmonary resusci- i tation. Annu Rev Med 1980;31:453-62.

45 Mandel LP, Cobb LA. CPR training in the community. Ann Emerg Med 1985;14:669-71.

46 Yusuf $S$, Collins $R$, Peto $R$, et al. Intravenous and intracoronary fibrinolytic therapy in acute myocardial infarction: overview of results on mortality, reinfarction and side-effects from 33 randomized controlled trials. Eur Heart $\mathcal{F}$ 1985;6:556-85.

47 Clyde C, Kerr A, Varghese A, Wilson C. Defibrillators in general practice. $\mathrm{Br} \mathrm{Med} \mathcal{F}$ 1984;289:1351-3.

48 Lowenstein SR, Hansbrough JF, Libby LS, Hill DM, Mountain RD, Scoggin CH. Cardiopulmonary resuscitation by medical and surgical house-officers. Lancet 1981;ii:679-81.

49 Casey WF. Cardiopulmonary resuscitation: a survey of standards among junior hospital doctors. $\mathcal{F}$ Soc Med 1984;77:921-4.

50 Skinner DV, Camm AJ, Miles S. Cardiopulmonary resuscitation skills of preregistration house officers. Br Med F 1985;290:1549-50. 


\section{Notices}

\section{British Cardiac Society}

The Autumn Meeting will be held at the Wembley Conference Centre, London, on 24 to 26 November 1987, and the closing date for receipt of abstracts will be 10 July 1987 .

The Annual General Meeting for 1988 will take place in Belfast on 23 and 24 March 1988, and the closing date for receipt of abstracts will be 4 January 1988.

\section{Cardiac Society of Australia and New Zealand}

The 35th Annual Scientific Meeting of the Cardiac Society of Australia and New Zealand will be held in Melbourne on 2 to 5 August 1987. Inquiries to: $\mathrm{Mr}$ K J Wickham, PO Box 235, North Balwyn 3104, Australia.

\section{Health education}

The XIII World Conference on Health Education will be held in Houston on 28 August to 2 September 1988. For further information write to the US Host Committee, PO Box 20186, Suite 902, Houston, Texas 77225, USA.

\section{Correction}

Editorial: Twenty years of prehospital coronary care $J S$ Geddes-we apologise for an error in the December 1986 issue (volume 56: page 491, right hand column, second paragraph, lines 3 and 4) where "hospital morbidity was only 9\%" should read "hospital mortality was only $9 \%$ ". 